\title{
EVOLUCIÓN NA XERACIÓN DE RESIDUOS AO LONGO DAS CADEAS DE SUBMINISTROS NAS ECONOMÍAS IBÉRICAS: ANÁLISE COMPARATIVA DE ESPAÑA E PORTUGAL
}

Soraya M. Ruiz-Peñalver ${ }^{1}$, Nuno Marques da Costa ${ }^{2}$

Margarida Queirós ${ }^{2}$ José A. Camacho ${ }^{1}$.

${ }^{1}$ Instituto Universitario de Investigación de Desenvolvemento Rexional, Universidade de Granada ${ }^{2}$ Centro de Estudos Xeográficos, Universidade de Lisboa (Portugal)

Resumo. Nas últimas décadas a xeración de residuos converteuse nun dos principais problemas medioambientais debido ao impacto que exerce unha incorrecta xestión dos mesmos sobre o medio natural. Perante este contexto, foise propagando unha maior preocupación ambiental na que a redución do volume de residuos é a súa principal premisa. No caso da Unión Europea (UE), o obxectivo da lexislación en materia de xestión de residuos centrouse na prevención e na reciclaxe para tender cara un crecemento económico moito máis sostible. Porén, e malia os logros acadados, é necesario seguir avanzando nesta liña xa que moitos membros, especialmente, os do Sur de Europa, aínda se afastan dos obxectivos propostos para 2020. Por iso, o obxectivo deste traballo é aplicar unha metodoloxía Análise de Ciclo de vida Input-Output (EIO-LCA nas súas siglas en inglés) para analizar o volume e tipoloxía de residuos xerados directa e indirectamente en cada elo da cadea de subministros das actividades económicas de España e Portugal.

Palabras chave: Cadeas de subministro, xeración de residuos, subministradores directos e indirectos

\begin{abstract}
In recent decades waste generation has become one of the main environmental problems due to the impact that an incorrect management exerts on nature. Consequently, a greater environmental awareness has been spreading so that waste reduction has become its main premise. In the case of the European Union (EU), the aim of the waste legislation is based on prevention and recycling towards a more sustainable economic growth. However, despite the achievements, it is necessary to continue advancing in this line since many Members, especially those from Southern Europe, are still far away from the 2020 objectives. Therefore, the aim of this paper is to apply an Economic Input-Output Life Cycle Analysis (EIO-LCA) to analyze the volume and type of waste generated directly and indirectly in each link of the supply chain of the economic activities in Spain and Portugal.
\end{abstract}

Keywords: Supply chain, waste generation, direct and indirect suppliers

\section{Introdución}

Un dos principais problemas ambientais aos que se enfronta a sociedade do século XXI, é como reducir o gran volume de residuos xerado a diario. En efecto, a senda de crecemento económico que seguiu a economía mundial supuxo a produción dunha maior cantidade e variedade de bens e servizos, que tamén foi asociada a unha maior xeración de residuos, cuxa mitigación supón un gran reto nas esferas ambiental, social e económica. Como consecuencia diso, xestouse a nivel global unha maior concienciación ambiental que se traduciu no desenvolvemento dunha normativa moito máis esixente en materia de xestión de recursos e residuos para converxer cara un crecemento económico máis sostible. A UE non se mantivo allea a este feito e dende as súas orixes estivo implicada na protección do medio ambiente (Ruiz, 2016; Ruiz et al., 2014) promovendo o desapareamento entre crecemento económico e xeración de residuos. De feito, nos últimos 15 anos as propostas 
lexislativas levadas a cabo pola UE tenderon cada vez máis a un uso máis sostible dos recursos naturais, estimulando a prevención e a reciclaxe de residuos (Milios, 2018), tendencia que se fixo moito máis evidente logo da entrada en vigor da actual Directiva Marco de Residuos (Directiva 2008/98/CE) e da adopción en 2015 da Estratexia de Economía Circular (COM (2015) 614 final). Porén, e malia os logros acadados, é necesario seguir avanzando nesta liña xa que moitos membros, especialmente do Sur de Europa, aínda se afastan dos obxectivos propostos para 2020 (Pires et al., 2011).

Nembargantes, un paso previo á prevención é a cuantificación do volume de refugallos xerados no eido da UE para constatar a efectividade das políticas en materia de xestión de residuos. Con este propósito, nos últimos anos observouse unha maior publicación de artigos académicos sobre este tema. Entre eles, cómpre destacar aqueles estudos baseados na Análise do Ciclo de Vida (LCA) do produto, unha ferramenta que realiza unha análise completa do impacto que ten un produto ao longo de toda a súa vida.

Porén, o modelo presenta unha serie de desvantaxes que o fan menos exacto ca outros modelos que combinan LCA con outras metodoloxías (Hoogmartens et al. 2014). Por outra banda, cómpre destacar outras metodoloxías que tratan de ampliar o marco Input-Output para unir nunha única análise aspectos ambientais, sociais e económicos (Nakamura e Kondo, 2009; Hendrickson et al., 2006; Doldán, 2002).

Por iso, o obxectivo deste traballo é realizar unha análise da evolución na xeración de residuos nos países que compoñen a Península Ibérica. Esta análise non se limita á comparación dos datos de xeración de residuos entre España e Portugal, senón que, para cada país aplícase unha metodoloxía EIO-LCA para analizar o volume e tipoloxía de residuos xerados directa e indirectamente en cada elo da cadea de subministros das actividades económicas de ámbalas dúas economías.

\section{Metodoloxía}

\subsection{Fontes de datos}

Para desenvolver o modelo EIO-LCA foi necesaria a utilización de dúas fontes primarias. Por unha banda, as táboas input-output de ámbolos dous países para o ano 2014 procedentes da World Input-Output Database (WIOD, 2016; Timmer et al., 2015), así como as estatísticas de xeración de residuos desagregadas por rama de actividade (Eurostat, 2018). Debido ás dimensións das táboas simétricas de ámbolos dous países, e a que moitas actividades, especialmente de servizos, non aparecen desagregadas nas estatísticas de residuos, as actividades económicas agrupáronse en 22 categorías como amosa o Anexo 1. Así mesmo, cómpre indicar que existe un cambio metodolóxico na clasificación estatística de residuos entre os anos 2007 e 2014, non existindo algunhas das tipoloxías de residuos consideradas dun ano para outro. Porén, consideráronse 33 categorías de residuos como amosa o Anexo 2.

\subsection{Metodoloxía EIO-LCA}

Neste documento aplícase unha metodoloxía cuantitativa baseada na aplicación do modelo híbrido EIO-LCA, que une nun mesmo estudo a análise da xeración de residuos para cada actividade económica ao longo de toda a súa cadea de subministros combinando a análise LCA e o modelo Input-Output. Esta ferramenta baséase no modelo de demanda de Leontief, representado en forma matricial na ecuación (1):

$$
\mathrm{X}_{\text {TOTAL }}=(\mathrm{I}-\mathrm{A})^{-1} \text { y (1) }
$$

Así pois, nunha economía con $n$ ramas de actividade, ХТотАL amosa o valor da produción do conxunto da economía para satisfacer á demanda final representada por y. I é a matriz 
identidade, unha matriz cadrada de orde nxn e diagonal, é dicir, todos os elementos desta matriz son 0 , agás os da súa diagonal principal que son 1 e A é a matriz de coeficientes técnicos, unha matriz cadrada de orde $n x n$ na que cada elemento $a_{i j}$ indica os inputs ou consumos intermedios que unha actividade $i$ require da rama $j$ por unidade monetaria de output. A matriz (I-A)-1 é a inversa da matriz de Leontief (I-A), e indica as necesidades totais de inputs ou consumos intermedios que necesita unha rama de actividade doutras para obter unha unidade de produción. Conforme a Miller e Blair (2009), a matriz inversa de Leontief pódese caracterizar a través das series de Euler, e dado que cada elemento da matriz de coeficientes técnicos A é inferior ou igual a 1, as series infinitas de Euler converxen a un límite finito, que é a matriz inversa de Leontief:

$$
(I-A)^{-1}=I+A+A^{2}+A^{3}+A^{4}+\ldots
$$

É por iso polo que, a partir do modelo de demanda, podemos distinguir entre subministradores directos, é dicir, aqueles provedores que abastecen directamente a unha determinada actividade $i$, e indirectos, aqueles outros provedores que, aínda que non subministran directamente a esa actividade $i$, son provedores dos directos (Rodríguez et al., 2016; Ruiz et al., 2014). Esta secuencia de provedores denomínase cadea de subministros e as súas dimensións dependen da complexidade do ben ou servizo que se estea considerando. Neste senso, os efectos dos subministradores directos veñen dados "polo inicio da progresión dos coeficientes técnicos, concretamente sumando o efecto inicial e o efecto que se deduce dos multiplicadores da matriz A [...], namentres que os indirectos son os obtidos a partir da suma ata o infinito dos valores da progresión que restan" (Carrascal et al., 2013, pp. 40). Así pois, a produción obtida polos subministradores directos viría dada pola ecuación (3), namentres que a produción dos subministradores indirectos se obtería coa ecuación (4):

$$
\mathrm{X}_{\text {DIRECTOS }}=(\mathrm{I}+\mathrm{A}) \text { y }(3)
$$

$$
\mathrm{X}_{\text {INDIRECTOS }}=\left[(\mathrm{I}-\mathrm{A})^{-1}-(\mathrm{I}+\mathrm{A})\right] \text { y }(4)
$$

Nótese que a produción total $\mathrm{X}_{\mathrm{TOTAL}}$, tamén se pode obter agregando as ecuacións (3) e (4). A partir das ecuacións (1), (3) e (4) pódese estimar o volume de residuos xerados para o conxunto de subministradores (ecuación 5), para os directos (ecuación 6), ou para os indirectos (ecuación 7). Como se observa nas ecuacións (5), (6) e (7), para obter o volume de residuos, cómpre definir a matriz $\mathrm{E}$ ou matriz de impacto ambiental (neste caso matriz de xeración de residuos), cadrada de orde $n x n$ e diagonal. Neste caso, a súa diagonal principal amosa o volume de residuos xerados por cada euro de produto total para cada unha das ramas de actividade consideradas (Hendrickson et al., 2006; 1998).

$$
\begin{aligned}
\mathrm{R}_{\text {TOTAL }} & =\mathrm{E} \mathrm{X}_{\text {TOTAL }}(5) \\
\mathrm{R}_{\text {DiReCTOS }} & =\mathrm{E} \mathrm{X}_{\text {DiRECTOS }}(6) \\
\mathrm{R}_{\text {INDIRECTOS }} & =\mathrm{E} \mathrm{X}_{\text {INDIRECTOS }}(7)
\end{aligned}
$$

\section{Resultados}

Antes de aplicar a metodoloxía EIO-LCA para analizar o volume de residuos total e o xerado directa e indirectamente para cada país, cómpre ter en conta certas consideracións. As dimensións social, económica e ambiental son totalmente distintas en ámbolos dous países, se ben a poboación española cuadruplica á portuguesa, a especialización económica difire entre ámbolos dous países, e como non, o volume de residuos en ámbolos dous territorios será distinto. En efecto, a táboa 1 amosa un extracto da estrutura produtiva de ámbolos dous países para o período 2007-2014, onde as diferenzas son evidentes. Porén, en ámbalas dúas economías obsérvase unha notable caída do valor das variables consideradas, motivada pola 
crise financeira e económica cuxos efectos comezaron a se albiscar en 2008, caída que tende a ser moito máis evidente no caso de España que no de Portugal, se ben o valor engadido caeu nun 5,5\% e nun 3,4\% durante 2007-2014 en España e en Portugal respectivamente, namentres que a produción o fixo nun $15,4 \%$ e un $6,9 \%$ para os mesmos países. Así mesmo, amósase que en 2014 ningún deles recuperara os valores previos á crise.

Táboa 1. Extracto da estrutura produtiva de España e Portugal. 2007-2014. Millóns de euros.

\begin{tabular}{||l|l|l|l|l||}
\hline \multirow{2}{*}{} & \multicolumn{2}{|c|}{2007} & \multicolumn{2}{c||}{2014} \\
\cline { 2 - 5 } & \multicolumn{1}{|c|}{ ESP } & \multicolumn{1}{|c||}{ PORT } & \multicolumn{1}{c||}{ ESP } & \multicolumn{1}{c||}{ PORT } \\
\hline Consumo intermedio total & 1.212 .639 & 165.713 & 950.832 & 149.562 \\
\hline Consumo intermedio da produción interior & 1.017 .563 & 130.048 & 763.748 & 111.150 \\
\hline $\begin{array}{l}\text { Consumo intermedio procedente de } \\
\text { importacións }\end{array}$ & 195.076 & 35.665 & 187.084 & 38.412 \\
\hline Impostos netos sobre os produtos & 56.268 & 9.330 & 20.230 & 7.980 \\
\hline Valor engadido a prezos básicos & 1.003 .234 & 156.936 & 947.952 & 151.618 \\
\hline Marxes internacionais de transporte & 12.640 & 2.765 & 13.195 & 2.565 \\
\hline Output a prezos básicos & 2.284 .781 & 334.743 & 1.932 .209 & 311.724 \\
\hline
\end{tabular}

FONTE: WIOD (2016).

Logo de aplicar a metodoloxía EIO-LCA, obtivéronse os resultados que amosan as seguintes táboas, nas que aparece o volume de residuos (kilogramos per cápita) conforme ao tipo de subministrador (total, directo e indirecto) por rama de actividade para cada país (táboas 2 e 3) e por tipo de residuo (táboas 3 e 4).

As táboas 2 e 3 amosan que, en 2007 ámbalos dous países xeraron unha cantidade semellante de residuos per cápita malia as diferenzas comentadas anteriormente. Se ben, a partir deste ano amósase unha tendencia decrecente motivada por dous aspectos principais. Por unha banda, as nefastas consecuencias que a crise financeira e económica tivo sobre o tecido produtivo de ámbalos dous países, reducindo o número de empresas e como resultado, o volume de residuos. Por outra, en 2008 entra en vigor a nova Directiva Marco de Residuos (DMR, Directiva 2008/98/CE) que inclúe unha serie de novidades con respecto á lexislación vixente ata o momento e establece obxectivos cuantitativos para reducir o volume de residuos xerado na UE e aumentar as taxas de reutilización e reciclaxe dos mesmos (Ruiz, 2016). Ámbalas dúas causas son as responsables de que en 2014 o volume de residuos se reducira nun 33,9\% e nun 57,8\% en España e Portugal respectivamente.

Así mesmo, en ámbalas dúas táboas obsérvase que en 2007 os sectores máis contaminantes en termos de xeración de residuos foron a construción e os servizos no caso de España, namentres que en Portugal destacan os servizos e a industria. Pola súa parte, en 2014 estes dous sectores mantéñense como os maiores produtores de residuos en Portugal malia a redución do volume de refugallos xerados (-56,4\% e 49,6\% respectivamente), namentres que en España a construción queda relegada pola industria e os servizos (cunha caída do $58,5 \%$ ), debido a que o devandito sector foi duramente apancado pola crise. Tanto en España como en Portugal hai que ter en conta que o sector servizos engloba un amplo espectro de ramas de actividade, que consideradas individualmente non producen unha gran cantidade de residuos, pero que, ao ser agregadas disparan o volume de refugallos xerados por este sector. Os Anexos 3, 4, 5 e 6 amosan unha desagregación da análise para as 22 actividades consideradas, onde este feito é máis visible. Así pois, se se fai unha análise pormenorizada, en 2007, a rama de actividade que produce máis residuos en ámbalos dous países é a construción con 1,1 e 0,3 toneladas per cápita para España e Portugal respectivamente, seguida das industrias extractivas con 0,6 e 0,3 toneladas por persoa para España e 
Portugal $^{1}$, e en terceiro lugar, a agricultura, gandaría e pesca no caso de España con 0,3 toneladas per cápita, namentres que en Portugal, o terceiro posto está ocupado pola fabricación de produtos minerais non metálicos con 0,3 toneladas per cápita. En canto ao ano 2014, esta tendencia cambia, se ben en España predomina a construción, a agricultura, gandaría e pesca, así como as actividades que se adican á recollida e xestión de residuos con 0,4 toneladas por persoa cada unha delas, en Portugal destacan a recollida e xestión de residuos con 0,3 toneladas per cápita, seguida da construción e a venda (retallista e comerciante por xunto) con 0,1 toneladas per cápita cada unha.

Así mesmo, cómpre destacar a supremacía dos subministradores directos fronte aos indirectos en canto ao volume de residuos xerados. Ao igual que nos países da contorna, isto débese á súa maior participación nas cadeas de subministros de cada actividade económica fronte aos subministradores indirectos, malia que hai que indicar que a participación destes últimos nas devanditas cadeas é cada vez maior por mor do grao de complexidade dos bens e servizos producidos (Rodríguez et al., 2014).

Táboa 2. Evolución da xeración de residuos por sector de actividade e tipo de subministrador. España.

\begin{tabular}{|l|l|l|l|l|l|l|l|r|r|}
\hline & \multicolumn{3}{|c|}{2007 (kg per cápita) } & \multicolumn{3}{c|}{2014 (kg per cápita) } & \multicolumn{3}{c|}{$\begin{array}{c}\text { Taxa de variación } \\
\text { interanual (\%) }\end{array}$} \\
\hline & Total & Dir. & Ind. & Total & Dir. & Ind. & Total & Dir. & Ind. \\
\hline $\begin{array}{l}\text { Agricultura, } \\
\text { gandaría e } \\
\text { pesca }\end{array}$ & 338,3 & 260,7 & 77,6 & 125,1 & 86,2 & 38,9 & $-63,0$ & $-66,9$ & $-49,9$ \\
\hline Minería & 580,9 & 278,7 & 302,2 & 400,8 & 389,4 & 11,3 & $-31,0$ & 39,7 & $-96,2$ \\
\hline Industria & 726,8 & 466,9 & 259,8 & 830,8 & 595,9 & 234,9 & 14,3 & 27,6 & $-9,6$ \\
\hline Construción & $1.056,7$ & 867,9 & 188,8 & 439,0 & 399,3 & 39,7 & $-58,5$ & $-54,0$ & $-79,0$ \\
\hline Servizos & 891,1 & 746,4 & 144,7 & 580,5 & 535,5 & 45,0 & $-34,9$ & $-28,3$ & $-68,9$ \\
\hline Total & $3.593,8$ & $2.620,6$ & 973,2 & $2.376,1$ & $2.006,3$ & 369,8 & $-33,9$ & $-23,4$ & $-62,0$ \\
\hline
\end{tabular}

FONTE: Elaboración propia.

Táboa 3. Evolución da xeración de residuos por sector de actividade e tipo de subministrador. Portugal.

\begin{tabular}{|l|l|l|l|l|l|l|l|l|l|}
\hline & \multicolumn{3}{|c|}{2007 (kg per cápita) } & \multicolumn{3}{c|}{2014 (kg per cápita) } & \multicolumn{3}{c|}{$\begin{array}{c}\text { Taxa de variación } \\
\text { interanual (\%) }\end{array}$} \\
\hline & Total & Dir. & Ind. & Total & Dir. & Ind. & Total & Dir. & Ind. \\
\hline Agricultura, & 20,3 & 15,6 & 4,7 & 4,7 & 3,7 & 1,1 & $-76,7$ & $-76,6$ & $-77,2$ \\
\hline
\end{tabular}

${ }^{1}$ A rama 19 "Outros servizos" non se considera malia o volume de residuos producido, xa que inclúe un gran número de actividades de servizos e, como se comentou anteriormente, elas non producen individualmente un inxente volume de residuos. 


\begin{tabular}{|l|l|l|l|l|l|l|l|l|l|}
\hline $\begin{array}{l}\text { gandaría e } \\
\text { pesca }\end{array}$ & & & & & & & & & \\
\hline Minería & 338,3 & 241,9 & 96,4 & 26,6 & 19,9 & 6,8 & $-92,1$ & $-91,8$ & $-93,0$ \\
\hline Industria & $1.191,4$ & 945,5 & 245,9 & 600,6 & 486,9 & 113,8 & $-49,6$ & $-48,5$ & $-53,7$ \\
\hline Construción & 342,5 & 287,8 & 54,7 & 145,1 & 127,1 & 18,0 & $-57,6$ & $-55,8$ & $-67,1$ \\
\hline Servizos & $1.426,0$ & $1.218,7$ & 207,3 & 621,8 & 549,4 & 72,4 & $-56,4$ & $-54,9$ & $-65,1$ \\
\hline Total & $3.318,5$ & $2.709,6$ & 609,0 & $\begin{array}{l}1.398, \\
9\end{array}$ & $1.186,9$ & 212,0 & $-57,8$ & $-56,2$ & $-65,2$ \\
\hline
\end{tabular}

FONTE: Elaboración propia.

En canto á tipoloxía de residuos, as táboas 4 e 5 amosan os resultados obtidos para España e Portugal respectivamente. Nelas obéervase que a tendencia foi unha reducción do volume de residuos producidos durante o período 2007-2014, malia que hai certas excepcións². No caso de España aumentaron principalmente os residuos de separación (categoría 26), os residuos metálicos férreos (categoría 8), pilas e acumuladores (categoría 20), lodos e efluentes industriais (categoría 5), residuos metálicos non férreos (categoría 9), materiais mesturados (categoría 25), equipos refugados (categoría 18) e residuos téxtiles (categoría 16). Pola súa parte, en Portugal aumentaron os vehículos refugados (categoría 19), residuos que conteñen PCB (categoría 17), residuos de separación (categoría 26), residuos de vidro (categoría 11), así como residuos metálicos férreos e non férreos (categorías 8 e 9). Ao igual ca nas táboas 3 e 4, ao distinguir por tipo de residuo e subministrador, obsérvase que os subministradores directos son os maiores xeradores de residuos por formar parte da cadea de subministros para a produción dun determinado ben ou servizo. Ademais, a ferramenta EIO-LCA permite identificar para cada rama de actividade o elo da cadea de subministros que xera máis volume de residuos, permitindo aos xestores de política en materia de residuos desenvolver plans sectoriais para estimular a minimización do volume de refugallos. Os Anexos 5 e 6 amosan a xeración de residuos por rama de actividade e por tipoloxía de residuo para o conxunto de subministradores. Así pois, en 2007 a construción foi o sector que máis refugallos xerou tanto en España como en Portugal. No caso de España, os subministradores directos foron os responsables de xerar 0,8 toneladas per cápita, sendo a industria extractiva a que tivo unha maior importancia relativa en canto a volume de residuos xerados. Finalmente, a figura 1 amosa a evolución e tendencia seguida por ámbalos dous países en materia de xeración de residuos. De certo, Portugal tivo un comportamento

\footnotetext{
2 Debido a que entre 2007 e 2014 houbo un cambio na metodoloxía de clasificación de residuos, hai certos valores que teñen taxas de variación bastante elevadas, xa que en 2014 existían categorías que en 2007 non existían ou estaban agregadas noutras. Isto ocorre principalmente coas categorías 30 a 33, polo que non se van considerar.
} 
moito máis favorable ca España. Porén, a liña de tendencia polinómica de segundo grao indica un certo repunte a partir de 2013.

Táboa 4. Evolución da xeración de residuos por tipoloxía de residuo e tipo de subministrador. España.

\begin{tabular}{|c|c|c|c|c|c|c|c|c|c|}
\hline & \multicolumn{3}{|c|}{2007 (kg per cápita) } & \multicolumn{3}{|c|}{2014 (kg per cápita) } & \multicolumn{3}{|c|}{$\begin{array}{l}\text { Taxa de variación media } \\
\text { anual acumulativa (\%) }\end{array}$} \\
\hline & Total & Dir. & Ind. & Total & Dir. & Ind. & Total & Dir. & Ind. \\
\hline 1 & 4,9 & 3,8 & 1,1 & 3,3 & 2,6 & 0,6 & $-5,5$ & $-4,9$ & $-7,8$ \\
\hline 2 & 17,2 & 11,3 & 5,9 & 13,0 & 9,9 & 3,2 & $-3,9$ & \begin{tabular}{|l|}
$-1,9$ \\
\end{tabular} & $-8,5$ \\
\hline 3 & 8,0 & 6,3 & 1,7 & 6,2 & 5,3 & 0,9 & $-3,6$ & \begin{tabular}{|l|}
$-2,4$ \\
\end{tabular} & $-9,0$ \\
\hline 4 & 34,4 & 26,3 & 8,1 & 14,0 & 11,4 & 2,6 & $-12,0$ & $-11,3$ & $-14,9$ \\
\hline 5 & 9,2 & 6,0 & 3,2 & 15,2 & 11,2 & 4,1 & 7,5 & 9,3 & 3,5 \\
\hline 6 & - & - & - & 5,5 & 4,1 & 1,4 & & & \\
\hline 7 & 14,6 & 12,2 & 2,4 & 7,1 & 6,5 & 0,6 & $-9,7$ & \begin{tabular}{|l|}
$-8,5$ \\
\end{tabular} & $-17,8$ \\
\hline 8 & 47,8 & 35,1 & 12,7 & 98,3 & 76,0 & 22,2 & 10,8 & 11,7 & 8,3 \\
\hline 9 & 6,1 & 4,5 & 1,6 & 9,4 & 7,2 & 2,2 & 6,5 & 7,0 & 4,8 \\
\hline 10 & 19,2 & 14,0 & 5,2 & 13,8 & 11,1 & 2,8 & $-4,6$ & $-3,3$ & $-8,6$ \\
\hline 11 & 33,0 & 26,4 & 6,6 & 23,4 & 21,0 & 2,4 & $-4,8$ & $-3,2$ & $-13,4$ \\
\hline 12 & 103,8 & 81,3 & 22,5 & 66,4 & 56,2 & 10,2 & $-6,2$ & $-5,1$ & $-10,7$ \\
\hline 13 & 9,6 & 7,9 & 1,7 & 5,0 & 4,5 & 0,5 & $-8,9$ & $-7,7$ & $-16,7$ \\
\hline 14 & 36,1 & 29,6 & 6,5 & 23,8 & 20,7 & 3,1 & $-5,8$ & \begin{tabular}{|l|}
$-5,0$ \\
\end{tabular} & $-10,2$ \\
\hline 15 & 42,6 & 30,4 & 12,2 & 23,0 & 18,3 & 4,7 & $-8,4$ & $-7,0$ & $-12,7$ \\
\hline 16 & 2,0 & 1,7 & 0,3 & 2,4 & 2,2 & 0,2 & 2,1 & 3,2 & $-6,3$ \\
\hline 17 & 0,2 & 0,1 & 0,1 & 0,0 & 0,0 & 0,0 & $-18,1$ & $-17,1$ & $-19,8$ \\
\hline 18 & 4,5 & 3,8 & 0,8 & 5,3 & 4,7 & 0,5 & 2,2 & 3,3 & $-4,9$ \\
\hline 19 & 21,9 & 18,3 & 3,6 & 15,1 & 13,9 & 1,2 & $-5,1$ & $-3,9$ & $-14,1$ \\
\hline 20 & 2,8 & 2,3 & 0,5 & 5,4 & 4,9 & 0,5 & 9,6 & 11,1 & $-0,3$ \\
\hline 21 & 83,4 & 68,0 & 15,4 & 39,4 & 32,0 & 7,4 & $-10,1$ & $-10,2$ & $-9,9$ \\
\hline 22 & 64,2 & 50,0 & 14,2 & 38,0 & 28,1 & 9,9 & $-7,2$ & \begin{tabular}{|l|}
$-7,9$ \\
\end{tabular} & $-5,0$ \\
\hline 23 & 313,8 & 242,1 & 71,7 & 95,8 & 66,2 & 29,6 & $-15,6$ & $-16,9$ & $-11,9$ \\
\hline 24 & 518,8 & 433,6 & 85,2 & 390,6 & 359,6 & 31,0 & $-4,0$ & $-2,6$ & $-13,5$ \\
\hline 25 & 25,3 & 20,7 & 4,6 & 38,7 & 30,3 & 8,4 & 6,2 & 5,6 & 8,9 \\
\hline 26 & 22,2 & 14,3 & 7,9 & 265,7 & 197,0 & 68,8 & 42,5 & 45,5 & 36,1 \\
\hline 27 & 41,1 & 27,4 & 13,7 & 30,9 & 22,7 & 8,2 & $-4,0$ & $-2,6$ & $-7,1$ \\
\hline 28 & $1.070,6$ & 878,9 & 191,8 & 152,6 & 133,3 & 19,3 & $-24,3$ & $-23,6$ & $-28,0$ \\
\hline 29 & 814,4 & 441,5 & 372,9 & 477,0 & 448,2 & 28,8 & $-7,4$ & 0,2 & $-30,6$ \\
\hline 30 & 208,0 & 113,0 & 95,1 & 155,3 & 94,1 & 61,2 & $-4,1$ & \begin{tabular}{|l|}
$-2,6$ \\
\end{tabular} & $-6,1$ \\
\hline 31 & 2,5 & 1,9 & 0,6 & 319,5 & 290,4 & 29,1 & 99,7 & 105,3 & 72,8 \\
\hline 32 & 3,4 & 2,8 & 0,6 & 0,0 & 0,0 & 0,0 & $-47,6$ & $-48,2$ & $-45,1$ \\
\hline 33 & 8,1 & 5,3 & 2,8 & 16,9 & 12,5 & 4,3 & 11,0 & 13,1 & 6,3 \\
\hline & $3.593,8$ & $2.620,6$ & 973,2 & $2.376,1$ & $2.006,3$ & $2.376,1$ & $-5,7$ & $-3,7$ & 13,6 \\
\hline
\end{tabular}

FONTE: Elaboración propia.

Táboa 5. Evolución da xeración de residuos por tipoloxía de residuo e tipo de subministrador. Portugal.

\begin{tabular}{|l|l|l|l|l|l|l|l|l|l|l|}
\hline & \multicolumn{3}{|c|}{2007 (kg per cápita) } & \multicolumn{3}{c|}{$\begin{array}{c}\text { Taxa de variación media anual } \\
\text { acumulativa (\%) }\end{array}$} \\
\hline & Total & Dir. & Ind. & Total & Dir. & Ind. & Total & Dir. & Ind. \\
\hline 1 & 5,8 & 4,9 & 0,9 & 0,7 & 0,6 & 0,1 & $-25,6$ & $-25,4$ & $-26,9$ \\
\hline 2 & 21,4 & 17,6 & 3,8 & 11,4 & 9,4 & 2,1 & $-8,6$ & $-8,6$ & $-8,4$ \\
\hline 3 & 218,0 & 184,0 & 34,0 & 4,5 & 3,7 & 0,7 & $-42,6$ & $-42,7$ & $-42,4$ \\
\hline 4 & 265,3 & 234,7 & 30,6 & 22,6 & 19,0 & 3,5 & $-29,7$ & $-30,2$ & $-26,5$ \\
\hline 5 & 44,7 & 35,9 & 8,8 & 20,5 & 16,8 & 3,7 & $-10,5$ & $-10,3$ & $-11,6$ \\
\hline 6 & - & - & - & 16,2 & 12,8 & 3,4 & & & \\
\hline 7 & 22,9 & 19,5 & 3,4 & 2,5 & 2,1 & 0,3 & $-27,3$ & $-27,0$ & $-29,2$ \\
\hline 8 & 171,6 & 138,4 & 33,2 & 185,6 & 156,6 & 29,0 & 1,1 & 1,8 & $-1,9$ \\
\hline 9 & 12,9 & 10,5 & 2,4 & 14,5 & 12,4 & 2,2 & 1,7 & 2,4 & $-1,6$ \\
\hline
\end{tabular}




\begin{tabular}{|l|l|l|l|l|l|l|l|l|l|}
\hline 10 & 40,5 & 32,7 & 7,8 & 24,3 & 20,8 & 3,4 & $-7,0$ & $-6,2$ & $-11,0$ \\
\hline 11 & 45,2 & 35,3 & 9,9 & 50,0 & 41,3 & 8,7 & 1,5 & 2,3 & $-1,8$ \\
\hline 12 & 226,0 & 191,8 & 34,2 & 100,3 & 85,8 & 14,5 & $-11,0$ & $-10,9$ & $-11,5$ \\
\hline 13 & 101,2 & 86,4 & 14,8 & 9,1 & 7,4 & 1,7 & $-29,1$ & $-29,5$ & $-26,7$ \\
\hline 14 & 94,6 & 80,5 & 14,0 & 28,9 & 24,3 & 4,6 & $-15,6$ & $-15,7$ & $-14,8$ \\
\hline 15 & 117,1 & 91,4 & 25,7 & 29,2 & 24,5 & 4,6 & $-18,0$ & $-17,1$ & $-21,7$ \\
\hline 16 & 45,2 & 42,7 & 2,5 & 7,2 & 6,7 & 0,5 & $-23,0$ & $-23,2$ & $-20,5$ \\
\hline 17 & 0,0 & 0,0 & 0,0 & 0,0 & 0,0 & 0,0 & 3,5 & 3,2 & 4,7 \\
\hline 18 & 21,4 & 18,0 & 3,3 & 6,7 & 5,6 & 1,1 & $-15,2$ & $-15,3$ & $-14,7$ \\
\hline 19 & 0,9 & 0,8 & 0,2 & 5,1 & 4,3 & 0,8 & 27,5 & 27,7 & 26,6 \\
\hline 20 & 18,8 & 16,1 & 2,7 & 4,4 & 3,8 & 0,6 & $-18,6$ & $-18,6$ & $-18,5$ \\
\hline 21 & 47,4 & 41,4 & 6,0 & 7,8 & 6,8 & 1,0 & $-22,7$ & $-22,7$ & $-22,4$ \\
\hline 22 & 52,1 & 45,9 & 6,2 & 7,9 & 7,0 & 0,9 & $-23,7$ & $-23,6$ & $-24,0$ \\
\hline 23 & 13,3 & 10,5 & 2,8 & 1,9 & 1,5 & 0,4 & $-24,4$ & $-24,5$ & $-23,9$ \\
\hline 24 & 631,4 & 538,9 & 92,5 & 429,3 & 378,8 & 50,5 & $-5,4$ & $-4,9$ & $-8,3$ \\
\hline 25 & 73,9 & 63,5 & 10,4 & 34,1 & 29,3 & 4,9 & $-10,4$ & $-10,5$ & $-10,2$ \\
\hline 26 & 40,3 & 29,4 & 10,9 & 45,0 & 36,0 & 9,0 & 1,6 & 2,9 & $-2,6$ \\
\hline 27 & 85,0 & 63,8 & 21,2 & 65,9 & 53,1 & 12,8 & $-3,6$ & $-2,6$ & $-7,0$ \\
\hline 28 & 282,1 & 227,8 & 54,3 & 92,1 & 79,5 & 12,6 & $-14,8$ & $-14,0$ & $-18,8$ \\
\hline 29 & 600,8 & 433,6 & 167,2 & 63,0 & 50,0 & 13,0 & $-27,5$ & $-26,6$ & $-30,5$ \\
\hline 30 & 17,7 & 12,7 & 5,0 & 34,6 & 23,9 & 10,8 & 10,0 & 9,4 & 11,6 \\
\hline 31 & 0,6 & 0,5 & 0,2 & 62,6 & 54,4 & 8,2 & 92,1 & 95,8 & 76,5 \\
\hline 32 & 0,0 & 0,0 & 0,0 & 0,3 & 0,2 & 0,0 & 102,0 & 107,4 & 81,6 \\
\hline 33 & 0,4 & 0,3 & 0,1 & 10,5 & 8,3 & 2,2 & 58,6 & 59,5 & 55,6 \\
\hline & $3.318,5$ & $2.709,6$ & 609,0 & $1.398,9$ & $1.186,9$ & 212,0 & $-11,6$ & $-11,1$ & $-14,0$ \\
\hline
\end{tabular}

FONTE: Elaboración propia.

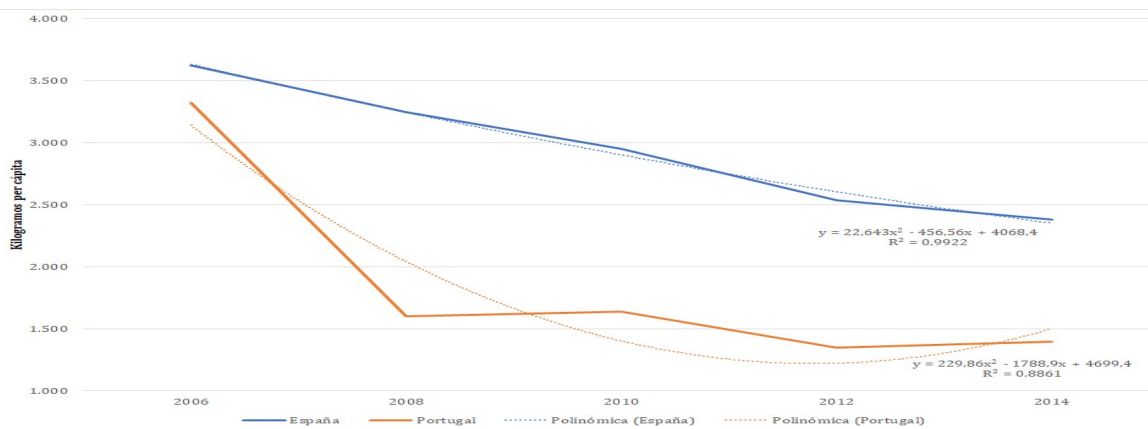

Figura 1. Evolución e tendencia do volume de residuos xerados. FONTE: Elaboración propia 4. Conclusións

O obxectivo deste traballo era aplicar unha metodoloxía EIO-LCA para analizar a evolución do volume de residuos xerados directa e indirectamente en cada elo da cadea de subministros das actividades económicas de España e Portugal durante 2007-2014.

Os resultados obtidos amosan a importancia relativa dos subministradores directos e indirectos no valor engadido de ámbalos dous países, se ben os procesos produtivos con cadeas de subministros máis longas aumentan o devandito valor, pero tamén tenden a incrementar o volume de residuos. Ademais, este modelo permite identificar o ela da cadea de subministros que é máis contaminante en termos de xeración de residuos, sendo unha ferramenta fundamental para o desenvolvemento de políticas sectoriais e ambientais. Os resultados tamén amosan unha tendencia decrecente na xeración de refugallos tanto en España como en Portugal. Porén, o país luso tivo un comportamento máis favorable, xa que durante 2007-2014 o valor engadido e a produción final diminuíron nun 3,4\% e nun 6,9\% respectivamente, e o volume de residuos nun $57,8 \%$. Pola súa banda, o valor engadido e a 
produción en España caeron un 5,5\% e un 15,4\% respectivamente, sendo a taxa de variación do $33,9 \%$. Estes datos non son determinantes para concluír a existencia ou non de desapareamento entre produción e xeración de residuos, entre outros aspectos polas características peculiares do período considerado. Porén, a redución no volume de residuos en ámbalos dous casos é moi superior á caída do valor engadido e da produción, polo que sería necesario realizar un seguimento da tendencia para acadar os obxectivos propostos pola UE para o ano 2020. De todo o anterior despréndese que unha das principais fortalezas da ferramenta EIO-LCA é que permite integrar a dimensión económica e ambiental nun único modelo coherente que considera neste caso, a xeración de residuos, as relacións inter e intraindustriais, así como os elementos que forman a demanda final dunha economía. Así pois, a consideración da demanda final neste tipo de modelos é decisiva xa que calquera cambio nos seus compoñentes alterará a produción final, así como o volume de residuos xerado. Neste senso, un cambio nos compoñentes da demanda final (consumo público e privado, formación bruta de capital e exportacións), especialmente no consumo (que ten un peso decisivo dentro da demanda final) tería un efecto moi positivo para tender cara un crecemento económico moito máis sostible.

\section{Referencias bibliográficas}

Carrascal, A.; Fernández, M.; Pereira, X. (2013): “Generación de residuos derivados del turismo receptor en Galicia”, Revista Galega de Economía, 22(1), pp. 31-50.

DOLDÁN, X.R.; CHAS, M.L. (2002): “Análisis de la integración de las cuentas económicas y ambientales del monte". Revista Galega de Economía, 11 (2), pp. 1-18.

Eurostat (2018): Datos de generación de residuos. Recuperado de: http://ec.europa.eu/eurostat/data/database

Hendrickson, C.; Horvath, A.; Joshi, S.; Lave, L. (1998): "Economic input-output models for environmental life cycle assessment", Policy Analysis, 32(7), pp. 73-86.

Hendrickson, C.; Lave, L.; MatThews, H. (2006): Environmental life cycle assessment of goods and services: an input-output approach. Washington: Resources for the future

Hoogmartens, R.; VAn PASSEL, S.; VAn ACKeR, K.; Dubois, M. (2014): “Bridging the gap between LCA, LCC and CBA as sustainability assessment tools, Environmental Impact Assessment Review, 48, pp. 27-33

Milios, L. (2018): "Advancing to a Circular Economy: three essential ingredients for a comprehensive policy mix", Sustainability Science, 13(3), pp. 861-878

MilleR, R.E.; BlaiR P. (2009): Input-Output analysis: foundations and extensions. New York: Cambridge University Press

NAKAMURA, S.; Kondo, Y. (2009): Waste input-output model: concepts and application to industrial ecology. Netherlands: Springer Science \& Springer Media

Pires, A.; Martinho, G.; ChAnG, N.B. (2011): "Solid waste management in European countries: A review of systems analysis tecniques", Journal of Environmental Management, 92(4), pp. 1033-1050

RodRíGUEZ, M.; RuIZ, S.M.; CAMACHO, J.A. (2016): “An estimation of the evolution of waste generated by direct and indirect suppliers of the Spanish paper industry", Waste Biomass Valorization, 7(3), pp. 635644

RuIz, S.M. (2016): La sostenibilidad en un sistema productivo globalizado: el papel y el cartón, ¿residuo o materia prima? Granada: Universidad de Granada

RuIZ, S.M.; RodRíGUEZ, M.; CAMACHO, J.A. (2014): “Direct and indirect generation of waste in the Spanish paper industry", Waste Management, 34(1), pp. 3-11

Timmer, M.P.; DietZenbacher, E.; Los, B.; STEHRER, R.; DE VRIES, G.J. (2015): “An illustrated user guide to the World Input-Output Database: the case of global automotive production", Review of International Economics, 23, pp. 575-605

WIOD (2016): Waste Input-Output Database. Recuperado de: http://www.wiod.org/database/wiots16 
Anexo 1. Clasificación das actividades económicas.

\begin{tabular}{|lll|}
\hline Núm. & NACE Rev. 2 & Actividade \\
1 & {$[01-03]$} & Agricultura, gandaría, caza, silvicultura e pesca \\
2 & {$[04]$} & Industrias extractivas \\
3 & {$[10-12]$} & Industria da alimentación, fabricación de bebidas e industria do tabaco \\
4 & {$[13-15]$} & Industria téxtil \\
5 & {$[16]$} & Industria da madeira e da cortiza, agás mobles; cestería e espartaría \\
6 & {$[17-18]$} & Industria do papel, artes gráficas e reprodución de soportes grabados \\
7 & {$[19]$} & Coque e refino de petróleo \\
8 & {$[20-22]$} & Industria química, farmacéutica, produtos de caucho e de plástico \\
9 & {$[23]$} & Fabricación de produtos minerais non metálicos \\
10 & {$[24-25]$} & Fabricación de produtos metálicos, agás maquinaria e equipo \\
11 & {$[26-30]$} & Fabricación de produtos informáticos, electrónicos e ópticos, material e \\
equipo eléctrico, vehículos de motor e outro equipo de transporte \\
12 & {$[31-33]$} & Fabricación de mobles, outras industrias manufactureiras, reparación e \\
instalación de maquinaria e equipo. \\
13 & {$[35]$} & Subministro de enerxía eléctrica, gas, vapor e ar acondicionado \\
14 & {$[36-40]$} & Recollida e tratamento de augas residuais; recollida, tratamento e \\
eliminación de residuos; servizos de aproveitamento; actividades de descontaminación e outros \\
servizos de xestión de residuos \\
15 & {$[41-43]$} & Construción \\
16 & {$[45-47]$} & Venda retallista e comerciante ao xunto \\
17 & {$[49-53]$} & Transporte e almacenamento \\
18 & {$[55-56]$} & Servizos de aloxamento e servizos de comidas e bebidas \\
19 & {$[84]$} & Administración pública \\
20 & {$[86-88]$} & Servizos sanitarios e de traballo social \\
21 & {$[85]$} & Educación \\
22 & {$[58-82,90-96]$} & Outros servizos \\
\hline \multicolumn{4}{|c}{} \\
\hline
\end{tabular}

Anexo 2 na Web da revista.

Revista Galega de Economía: http://www.usc.es/econo/RGE/benvidag.htm 